\title{
Caracterización de la industria de servicios de transporte forestal en Chile y estrategias competitivas de las firmas
}

\author{
Characterization of the forest transportation service industry in Chile \\ and their competitive strategies
}

\author{
ALEJANDRO ANDALAFT CH. ${ }^{1}$, RICARDO LANDEROS B. ${ }^{2}$, JULIAN PERRET G. ${ }^{3}$ \\ ${ }^{1}$ Departamento de Ingeniería Industrial, Universidad de Concepción, Casilla 160 C, Correo 3, Concepción, \\ Chile. E-mail: aandalaf@udec.cl \\ ${ }^{2}$ Forestal Mininco S.A., Casilla 399, Los Angeles, Chile. E-mail: rlanderos@formin.cmpc.cl \\ ${ }^{3}$ O'Higgins 420, Piso 7. Concepción, Chile. E-mail: jperret@abcap.cl
}

\begin{abstract}
SUMMARY
An analysis of the forest transport industry is made. The results are based on a survey of a select sample of 79 forest transport service firms, and interviews with clients and suppliers. The analysis allowed a detailed explanation of the whole competitive environment in which forest transport firms operate, determining a low attractive of the industry, hence their profitability. Cost leadership is the strategy that dominates the industry. Therefore, size is a relevant factor to improve the competitive position of the firm before its suppliers and clients. Size represents a series of decisions and strategic commitments through time with the forest transport industry. The analysis of some particular firms, based on the resourced based view of the firm and activities system and their segmentation into strategic groups, allowed to define and recognize the key activities and singularities that allow these firms to operate with advantages in efficiency and profitability, within low average performance business. Some large and medium size firms investment and development criteria have positioned them considerably better than another firms in the industry.
\end{abstract}

Key words: analysis of industry, resources, resources based view of the firm, activities map, competitive advantages.

\section{RESUMEN}

Se analiza la industria del transporte forestal. Los resultados se basan en una encuesta realizada a una muestra de 79 firmas de servicios de transporte de productos forestales primarios, entrevistas con los clientes y proveedores. El análisis explica el contexto competitivo en el cual se desempeñan las firmas de transporte forestal, determinándose un bajo atractivo actual de la industria, y por lo tanto de las posibilidades de renta de las firmas. La estrategia que domina a la industria es el liderazgo en costos. La escala o tamaño es relevante para mejorar la posición competitiva de la firma ante proveedores y clientes. El tamaño representa una serie de decisiones y compromisos estratégicos a través del tiempo con la industria. El análisis de las firmas basado en teoría de la firma y desarrollo de capacidades y actividades, y su segmentación en grupos estratégicos, permitió definir y reconocer las actividades clave y que las llevan a desempeñarse con ventajas en eficiencia y rentabilidad en una industria de bajo rendimiento promedio. Hay algunas firmas grandes y medianas consideradas exitosas porque tienen criterios de inversión y desarrollo que las han hecho estar considerablemente mejor posicionadas que el resto de las firmas de la industria.

Palabras clave: análisis de la industria, recursos, teoría de la firma, mapa de actividades, ventajas competitivas. 


\section{INTRODUCCION}

El transporte de carga debe alcanzar altos niveles de eficiencia, pues a las firmas se les exige obtener beneficios en un ambiente cada vez más competitivo y con un mercado oferente que crece (1).

El transporte terrestre es el más empleado en el sector forestal, dada su alta versatilidad y variedad de medios para acceder a las operaciones de terreno, centros procesadores y puntos de embarque y desembarque (2). En Chile el transporte terrestre forestal representaba aproximadamente el $45 \%$ del costo total de producción, sin considerar el transporte marítimo (3). Entonces, la industria de servicios asociada constituye un proveedor de primera importancia y su conocimiento es absolutamente necesario.

El trabajo se centra en caracterizar a la industria de servicios de transporte forestal en función de su tamaño, firmas, gestión, competitividad y estrategias de desarrollo. Identificar aquellas firmas que han sido exitosas en la industria y determinar los motivos del éxito.

El primer determinante fundamental de la utilidad de una firma es lo atractivo del sector industrial, por lo que comprender la estructura de éste permite a la firma adoptar una adecuada estrategia competitiva, a partir de una buena comprensión de las normas de competencia.

Porter (4) identificó estas normas de competencia y las englobó en cinco fuerzas competitivas: el ingreso de nuevos competidores, la amenaza de sustitutos, el poder de negociación de los compradores, el poder de negociación de los proveedores y la rivalidad entre los competidores existentes. Estas fuerzas están presentes en cualquier sector industrial y las firmas a través de sus estrategias pueden influir en las cinco fuerzas competitivas.

La posición relativa de una firma dentro de una industria es una cuestión central en la estrategia competitiva, ya que su ubicación determina si la utilidad de una firma está por arriba o por abajo del promedio del sector.

La base fundamental del desempeño sobre el promedio a largo plazo es una ventaja competitiva sostenida. Hay dos tipos básicos de ventajas competitivas que puede poseer una firma, costos bajos o diferenciación. Estas surgen de la estructura del sector industrial y son el resultado de la capacidad de una firma de lidiar con las cinco fuerzas mejor que sus rivales.

\section{MATERIAL Y METODOS}

El análisis estructural del sector industrial del transporte forestal está basado en los trabajos publicados al respecto por M. E. Porter. El análisis de posicionamiento, sustentación y competitividad de las firmas de la industria, grupos estratégicos y sistemas de actividades se orientó por los trabajos fundamentales de diversos autores de estrategias competitivas.

Para obtener una amplia base de datos que permitió analizar a la industria se utilizó el método de encuestas y entrevistas a las firmas, clientes y proveedores. La base de datos se procesó en computador mediante programas diseñados especialmente para tales efectos (5).

El primer paso en el análisis estructural dentro de los sectores industriales es caracterizar las estrategias de todos los competidores de importancia. Esto permite así clasificar el sector industrial en grupos estratégicos.

Un grupo estratégico es el conjunto de firmas en un sector industrial que sigue una misma o similar estrategia a lo largo de las dimensiones estratégicas. Las dimensiones estratégicas representan las posibles y diferentes opciones de estrategias que las firmas adoptan para competir. Por lo general existe un número pequeño de grupos estratégicos que capturan las diferencias esenciales entre las firmas en el sector industrial (6).

Estos grupos existen por varias razones, tales como fuerzas y debilidades diferentes al inicio de sus operaciones, diferentes épocas de ingreso al negocio y accidentes históricos. Sin embargo, una vez que se han formado los grupos, el potencial de utilidades de las firmas en distintos grupos estratégicos comúnmente es diferente, debido a que las cinco fuerzas competitivas generales no tendrán un impacto igual sobre diferentes grupos estratégicos.

La Teoría de la Empresa basada en recursos y capacidades sostiene que existen recursos que son el mayor determinante de la estrategia de una firma de negocios. La teoría comienza con dos generalizaciones básicas, existen diferencias sistemáticas entre las firmas pues controlan re- 
cursos que son necesarios para implementar estrategias y estas diferencias son relativamente estables. A estos supuestos básicos se agregan presunciones fundamentales derivadas de la economía, estas son: las diferencias en dotación de recursos que tienen las firmas causan diferencias de desempeño, y las firmas buscan aumentar, no necesariamente maximizar, su desempeño económico.

Nelson y Winter (7) muestran un caso extremadamente convincente en el que las firmas serían entidades esencialmente heterogéneas, caracterizadas por bases de recursos únicos. Esta condición es seguramente la presunción básica que permite construir importantes modelos estratégicos de la firma.

Foss (8) reconoce que probablemente la exposición más sistemática de que la teoría de la firma basada en recursos y capacidades permite lograr una ventaja competitiva está contenida en el artículo The Cornerstones of Competitive Advantage a Resourced Based View, cuyo autor es Peteraf (9) y fue publicado en el Strategic Management Journal en 1993. El artículo señala que existen cuatro características que deben tener los recursos para contribuir a una ventaja competitiva sostenida y que permiten que una firma logre retornos sobre normales sostenidos. La heterogeneidad de recursos genera rentas ricardianas o monopólicas. Límites ex post a la competencia evitan que las rentas se pierdan por la competencia. Límites ex ante a la competencia cuidan los costos que contrarrestan las rentas y la movilidad imperfecta de los factores asegura que los factores valiosos permanezcan en la firma y que se obtengan las rentas esperadas.

Mahoney y Pandian (10) sostienen que la estrategia puede ser mirada como una "búsqueda continua de renta", donde la renta es definida como el retorno en exceso de los costos de oportunidad de los recursos del propietario. La generación de tasas de retornos sobre normales es el enfoque de análisis de ventaja competitiva. En contraste con la teoría de mercados eficientes, la mayoría de los estudiosos de la teoría de la firma insiste en que es posible obtener rentas económicas en el corto plazo.

Las capacidades únicas de las firmas en términos de conocimiento técnico y habilidad de gestión son importantes recursos de heterogeneidad y pueden resultar en una ventaja competitiva sos- tenida. A pesar de la naturaleza de las rentas, la ventaja competitiva sostenida requiere que la condición de heterogeneidad persista. Si la heterogeneidad es un fenómeno de corta vida, las rentas de igual modo serán efímeras.

Markides y Williamson (11) señalan la importancia de distinguir las diferencias entre activos estratégicos y competencia central. Los activos estratégicos son activos que sustentan un costo de empresa o una ventaja diferenciadora en un mercado particular y que son imperfectamente imitables, imperfectamente substituibles e imperfectamente comerciables. Por otro lado, las competencias centrales son el pool de experiencias, conocimientos y sistemas que existen en la misma corporación y pueden ser desplegados para reducir costos o tiempos requeridos tanto para crear un nuevo activo estratégico o aumentar el stock de uno existente. Los autores sostienen que la real ventaja viene del aprovechamiento relacionado con la creación y acumulación de nuevos activos estratégicos más rápida y económicamente que la competencia.

La mayor contribución de la teoría de la firma es que explica las diferencias en el largo plazo en la rentabilidad de la firma que no puede ser atribuida a diferencias en las condiciones de la industria. Barney (12) argumenta que una firma puede obtener expectables ventajas si analiza la información acerca de los recursos que mantiene bajo control. Cuán largo tiempo estos recursos sean imperfectamente móviles, inimitables e insustituibles, impedirán que otras firmas imiten su estrategia.

La diversificación se apoya en la teoría de la firma basada en recursos y capacidades, y la teoría dice que "como consecuencia de sus operaciones normales, las firmas acumulan en forma gradual exceso de recursos". En principio estos recursos pueden ser transados en los mercados, sin embargo la presencia de costos de transacción puede impedir la venta de estos recursos en exceso. Esto particularmente podría ser el caso de recursos de conocimiento (13).

Kogut y Zander (14) dicen que las organizaciones saben más que lo que sus contratos pueden decir. Se pueden distinguir dos categorías de conocimiento, la información y el know how. Por información, nosotros entenderemos el conocimiento, el cual puede ser transmitido sin pérdida de integridad. El know how puede ser definido 
como la acumulación de experiencia práctica que permite a un individuo, grupo u organización hacer algo uniforme y eficientemente.

Es importante reagrupar las funciones en actividades, ya que la ventaja competitiva no puede entenderse considerando a una firma como un todo. Se origina de las muchas actividades discretas que lleva a cabo una firma en diseñar, producir, comercializar, entregar y apoyar su producto. Las firmas deben seleccionar un conjunto fundamentalmente diferente de actividades para lograr una combinación única de valor, en lugar de sólo desempeñar el mismo conjunto de actividades mejor que los competidores.

Las capacidades de una organización en cualquier punto del tiempo dan forma a los tipos de oportunidades de compromiso que se pueden explotar de manera realista. Las inversiones tanto en compromiso de recursos como en capacidades, debido a su naturaleza irreversible, pueden provocar la aparición y persistencia de ventajas (o desventajas) específicas de la compañía. Los costos de cambiar de idea sobre ellas exigen una fuerte atención al futuro por razones de supervivencia de la firma.

El desarrollo de capacidades implica selecciones que individualmente son pequeñas y frecuentes, más que individualmente importantes e infrecuentes. Las capacidades pueden asociarse como el enlace de retroalimentación entre actividades y dotación de recursos. La idea es que las capacidades específicas de la firma se creen gradualmente y se refuercen durante largos períodos. Así, problemas como la adquisición de habilidades y el aprendizaje se vuelven problemas estratégicos fundamentales (15). Si una empresa ha de sostener un desempeño superior, sus capacidades deben ser difíciles de imitar. Las barreras a la imitación más conocidas son aprendizaje, complejidad y mejoras.

Este aprendizaje se acumula en un fondo de conocimiento que tiende a ser más específico de la compañía y más inimitable cuando es tácito más que especificable, y cuando es sostenido colectivamente por miembros de la organización, en lugar de estar al alcance de uno o dos empleados. El conocimiento puede administrarse de manera que lo hagan menos probable de extenderse a los competidores.

\section{RESULTADOS Y DISCUSION}

A continuación se presentan los antecedentes generales de las firmas y la estructura de la industria en particular, la conformación de los grupos estratégicos y las fuentes de ventajas competitivas.

El mayor número de firmas entradas al rubro se produce en el período 1991-1995, que corresponde al período de auge del sector forestal. El ingreso de nuevos competidores al rubro ha tenido un descenso sostenido en los últimos años, debido al poco atractivo estructural de la industria y los bajos niveles de rentabilidad del rubro que contraen directamente la inversión.

Se encontró un $77 \%$ de firmas de transporte forestal familiares. Aquí se mantienen las mismas proporciones a través de los distintos tamaños. Existe una alta variabilidad en términos de tamaños, estructuras organizacionales, nivel de profesionalización e infraestructura. Se puede decir que a medida que aumenta el tamaño mejoran sus condiciones como firma.

El tamaño medio de la flota es de 12 camiones por firma, cifra que se ve distorsionada por la existencia de algunas grandes firmas. En la encuesta se clasificó a las firmas en tres tamaños: pequeñas (entre 1 y 6 camiones), medianas (entre 7-15 camiones) y grandes (16 o más camiones). Esto da origen a tres grupos estratégicos.

El $37 \%$ de la muestra son firmas pequeñas, constituidas como empresas de subsistencia, sin perspectivas de crecimiento y generalmente con presencia explícita de parientes en la sociedad, en la gestión y en el trabajo de chofer. Las medianas, un $43 \%$, se constituyen como firmas con estructuras más formales y un mayor grado de profesionalización. Las grandes firmas, un 20\% de la muestra, poseen considerables capitales de respaldo y estructuras que soportan su tamaño. Por lo general, están diversificadas tanto en sus servicios como en su cartera de clientes. Poseen objetivos de mediano y/o largo plazo y recursos invertidos en ellos, lo que les permite asegurar su presencia en el futuro.

La existencia de sistema de información administrativo escapa a la totalidad de firmas pequeñas y está poco presente en las medianas. El $39 \%$ de las firmas, principalmente grandes y medianas, han desarrollado programas hechos a medida para realizar un completo control sobre una 
o más áreas funcionales. Las áreas más controladas por dichos sistemas de gestión son los consumos, control de la producción y mantenimiento y reparaciones. Esto indica que la preocupación de las firmas se centra en mantener bajos sus costos y prestar un buen servicio a sus clientes.

Del total de las firmas de transporte un $41 \%$ tiene empresas relacionadas y de nuevo se aprecia una tendencia de crecimiento a medida que aumenta el tamaño. La diversificación de los negocios casi siempre responde a un proceso de integración vertical. Hay un grado importante de integración hacia los compradores, con firmas forestales o afines, aserraderos, empresas agrícolas y/o de compra de bosques. También existen, aunque en menor nivel integración vertical hacia los proveedores, con presencia de maestranzas para la fabricación de los propios carros y talleres mecánicos independientes.

Las firmas de transporte forestal son muy especializadas en clientes, lo que les hace crear un lazo de alta dependencia para con los compradores. Un 53\% de las firmas posee sólo un cliente, incluyendo este porcentaje a la totalidad de las firmas pequeñas. Un $41 \%$ de las firmas tienen diversificada su línea de transporte en 2 a 3 clientes. Sigue existiendo un cliente dominante, con una leve diversificación hacia otros clientes menores que les sirven para mantener trabajando su exceso de capacidad. El 6\% restante tiene más de 3 clientes relevantes. Es el caso de firmas grandes que realizan operaciones en más de una región.

Para el caso de la encuesta se analizaron las ventas, ventas por camión y relación deuda/activo fijo. A medida que aumenta el tamaño de las firmas aumenta su nivel de ventas por camión. En la relación deuda/activo fijo a través de los tamaños no se observan diferencias significativas. La estructura de financiamiento se mantiene proporcionalmente igual a través de los diferentes tamaños y en torno a valores cercanos al $30 \%$. A pesar de que los valores de la relación de deuda/activo fijo no son extremadamente altos, la composición y los plazos definen una situación bastante complicada. Gran parte de la deuda es de corto plazo, lo que genera problemas a muchas firmas porque les exige generar alta liquidez de manera continua para afrontar las obligaciones financieras.

El sector de transporte forestal se encuentra dominado por la acción de tres fuerzas principa- les: poder de los compradores, poder de los proveedores y rivalidad interna, representando las restantes escasa importancia en la actualidad.

Respecto al poder de negociación de los compradores, existe un dominio total de los compradores, quienes controlan completamente el mercado y los movimientos del sector industrial: crecimiento, rentabilidad mediante la fijación de tarifas y niveles de servicio exigidos. Lo anterior es crítico en este caso porque son pocas las empresas que dominan el negocio y demandan casi la totalidad de los servicios de transporte forestal. El poder de esta fuerza está dado por aspectos relacionados con los grandes volúmenes de compra en relación a las ventas totales del proveedor, características de servicio no diferenciado, con bajos costos de cambio dado el alto número de oferentes y la poca especificación del servicio. Finalmente, por concepto de costos, aspectos sociales y laborales y aspectos estratégicos de recursos y de capacidades, los compradores no plantean una real amenaza de integración hacia atrás.

Uno de los pocos factores estructurales que colabora a disminuir el poder relativo de esta fuerza es la oportunidad de transporte de los productos y su influencia en la eficiencia del sistema productivo. Además, en términos de la imagen pública del comprador, el desempeño y la inserción de las firmas de servicios en la comunidad constituye una preocupación vital del comprador.

En el transporte forestal el poder de negociación de los proveedores de financiamiento es el más importante. Su enorme influencia en el costo de posesión y los requerimientos de liquidez que implica sus cuotas pueden sobrepasar los rendimientos del rubro. Es opinión de muchos que las tasas de interés cobradas amenazan expropiar gran parte de sus rentas. Los proveedores es un grupo dominado por pocas firmas concentradas, sin productos sustitutos, vendiendo un insumo importante para el negocio del comprador y en donde este no constituye por sí solo un grupo importante para el proveedor.

Los demás proveedores, como petróleo, neumáticos y lubricantes, equipos de comunicaciones, taller, seguros, entre otros, no constituyen una fuerza muy relevante pues existen en gran número, se desarrollan en mercados atomizados, y presentan precios regulados por el mercado. 
Existe también un nivel considerable, aunque no exagerado, de rivalidad interna entre competidores. Lo anterior se debe al gran número de firmas existentes en el mercado cuyo servicio prácticamente no se diferencia entre unas y otras. Dicha rivalidad se ve regulada en gran parte por los propios compradores y por sus mecanismos de contratación que son los que en definitiva permiten determinados movimientos estratégicos como crecimientos y rotaciones. Existen además altas barreras de salida, marcadas por altos costos de salida y activos especializados con bajo valor de reventa, con un mercado alternativo muy limitado y barreras emocionales muy altas.

En el rubro del transporte forestal las barreras de entrada no son altas pues cualquier persona natural puede adquirir uno o más camiones, además, la reacción por parte de los compradores ante una nueva entrada no es alta pues la decisión final de acceso al mercado no depende de esfuerzos que realicen los competidores actuales. La atomización de las empresas y la poca presencia de firmas con un significativo poder relativo no permiten ejercer obstáculos a la entrada de nuevos actores al mercado. Sin embargo, la amenaza de ingreso es baja debido a los bajos niveles de rentabilidad con los que se trabaja. Esto desincentiva la inversión en camiones de los competidores existentes, y con mayor razón la de los potenciales.

En relación a los productos sustitutos, esta es la fuerza menos presente en el sector. Los transportistas de este sector trabajan en predios cuyas ubicaciones geográficas y condiciones morfológicas son prácticamente impenetrables para otros medios de transporte, por lo tanto se puede decir que en una primera aproximación no habría sustitutos.

La ventaja competitiva está relacionada con la estructura de la industria, con el grado de evolución de la empresa y con su escala o tamaño. El tamaño y el grado de evolución están directamente relacionados, el aumento de tamaño obliga a las firmas a perfeccionar su organización interna y mejorar sus sistemas de gestión. A medida que estas dos variables mejoran, la posición de la firma en la industria se hace más fuerte o menos vulnerable, se mejora su posición de costo y su nivel tecnológico. A medida que esto ocurre, la confiabilidad y eficiencia de la firma aumentan, produciéndose un mejor posicionamiento de la marca en el mercado.
Las firmas pequeñas se caracterizan por un bajo nivel de profesionalización, sistemas organizacionales informales, bajas tasas de inversión, carencia de instalaciones básicas y un alto nivel de dependencia del cliente. En estas circunstancias, si no hay un esfuerzo explícito o una inversión significativa de recursos, la firma está condenada a mantenerse subsistiendo por muchos años con ese mismo perfil, con los consiguientes perjuicios en términos de rentabilidad.

En el tiempo sólo algunas de estas firmas logran evolucionar y crecer para transformarse en medianas. Se debe recordar que la opción de crecimiento es una alternativa administrada en gran parte por los compradores, por lo que quienes hayan sido capaces de crecer en este mismo mercado poseen, por lo menos, el activo esencial que conforma el contacto y la historia previa con el comprador.

El tamaño por sí solo no les garantiza rentabilidad, ventajas competitivas o liderazgo. Aun cuando la mayoría de estas firmas ha adquirido un tamaño que les permite ser eficientes, o por lo menos significativos ante proveedores y clientes, existen muchas diferencias relevantes entre ellas. Por lo que muchas de ellas se mantendrán en forma permanente en este estado y sólo las que aprovechen las oportunidades de desarrollo estarán en condiciones de construir una ventaja competitiva.

Cuando estas firmas siguen creciendo e ingresan a la gran escala, la presencia de ventajas competitivas aumenta. Estas firmas cuentan con una cartera de clientes diversificada, una posición privilegiada de costo, una organización formal con presencia de profesionales en los niveles altos y tasa de inversión constante, lo que les permite en la mayoría de los casos ofrecer una mayor solidez. Tomando en cuenta el alto grado de especialización y compromiso en el rubro, la demanda se mantiene más estable y es posible reforzar y mejorar las capacidades que se han adquirido. A esta altura, y cuando se agrega a lo anterior las habilidades para coordinar el siguiente conjunto de conceptos: personal capacitado, buen clima en la organización, participación y compromiso, estabilidad laboral, etc., ya se puede hablar de tener una ventaja competitiva sostenible.

Finalmente es bueno recalcar que esta ventaja competitiva no es exclusiva de las firmas grandes, sin embargo, es el logro final de un proceso de desarrollo facilitado e incitado por la escala. El 


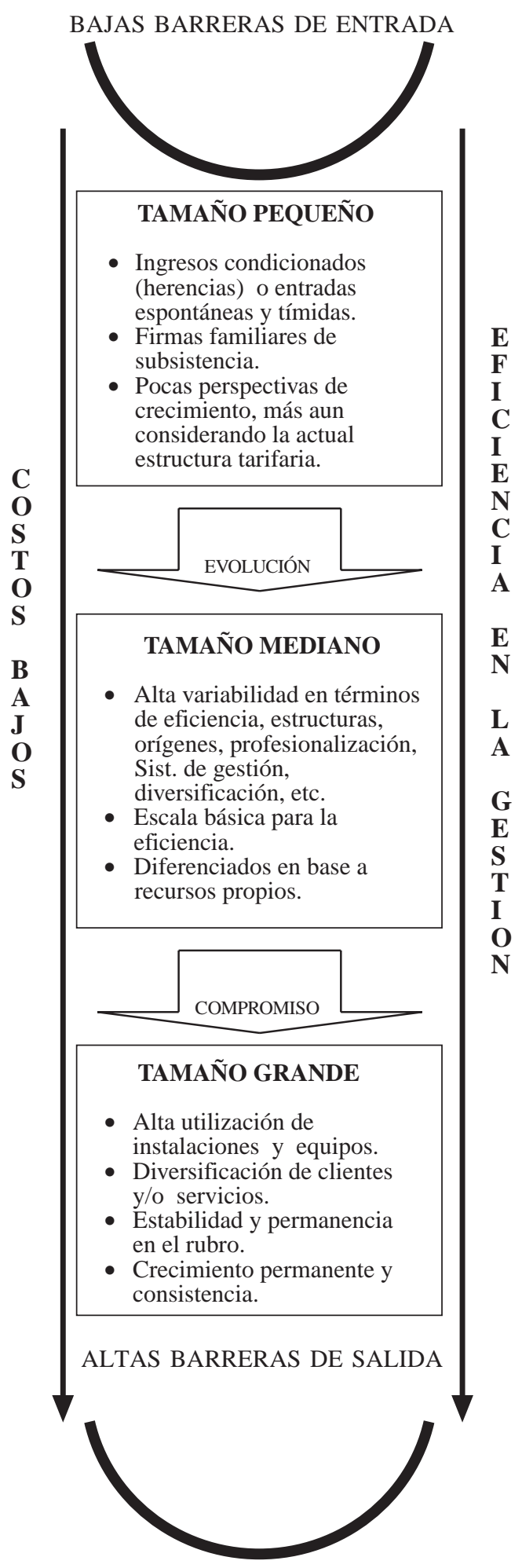

Figura 1. Modelo de ventaja competitiva de la industria.

Model of competitive advantage of the industry. modelo de ventaja competitiva propuesto para esta industria se presenta en la figura 1. Tomando en cuenta el origen de este sector industrial, creado para externalizar una función inicialmente interna de los compradores, se tiene que muchas de las firmas que entraron en los orígenes de la industria han consolidado lo que hoy constituye el grupo de gran escala. Siguiendo la pauta de formación del grupo de firmas grandes, puede decirse que el establecimiento de los grupos de menor escala responde en gran parte a ingresos efectivos recientes u orígenes espontáneos, no impulsado por necesidades reales o peticiones de los compradores.

La evolución, la experiencia y el tiempo de permanencia en el rubro condicionan el tamaño de las firmas; se tiene que los años de entrada y los orígenes de las firmas definen mucho de lo que hoy es cada uno de los grupos estratégicos. Las firmas más grandes están protegidas por grandes barreras de movilidad que por naturaleza atienden al grado de evolución de la firma y a su historia, y que por lo tanto son no adquiribles en el corto plazo. Para las firmas pequeñas es difícil pensar en transformarse en firmas de gran escala a menos que sea producto de la integración vertical o por enormes esfuerzos de diversificación de clientes. Para las firmas medianas, sin embargo, existen posibilidades de sortear tal barrera. Aunque no poseen un posicionamiento de la marca muchas poseen buenos índices de eficiencia y tienen un nexo significativo con los compradores.

Los grupos estratégicos prácticamente no difieren en el poder de negociación ante los compradores. El poder monopsónico y el grado de atomización de las firmas de transporte va más allá de la posición estratégica de un grupo, y aun cuando la escala de los grandes puede influir o favorecer algunos aspectos de los contratos, las condiciones generales se mantienen parejas para todos los grupos.

Por el lado del poder ante los proveedores la situación es distinta y se aprecian diferencias entre los distintos grupos estratégicos. El efecto natural de la escala son los descuentos por volumen. En las firmas grandes, la escala facilita la posesión y el desarrollo de capacidades relacionadas con la planificación, la solvencia y la profesionalización. Por esta razón los grandes siempre estarán en una posición relativa favorable o por lo menos competitiva ante los de proveedores. 
La amenaza de productos sustitutos es baja y homogénea para todos los grupos estratégicos. Lo anterior se debe a que factores como los niveles de diferenciación y/o posicionamiento de marca están prácticamente ausentes en el mapa de grupos estratégicos, luego no existirían barreras distintas en caso de existir una amenaza seria de sustitución.

Respecto de la rivalidad entre competidores, se aprecia un elevado potencial de rivalidad interna entre los grupos estratégicos, esto debido a que el mercado objetivo es similar para las firmas pequeñas y medianas. Sin embargo, el grupo de gran escala está más alejado de dicha rivalidad pues tiene más diversificada su cartera de clientes y una mayor amplitud geográfica de sus operaciones. Para todos hay una baja diferenciación en cuanto a los servicios.

A pesar del alto potencial de rivalidad, este no se manifiesta o desarrolla en forma agresiva. Como ya se ha dicho, el monopsonio regula todo movimiento estratégico posible, las oportunidades en que se puede competir son muy limitadas y restringen las competencias de las firmas y por ende la de los grupos estratégicos.

En la figura 2 se presenta un gráfico que relaciona a los grupos estratégicos y la intensidad de la rivalidad competitiva. El eje vertical representa la dimensión estratégica clave, que en este caso es el tamaño, que determina la posición de costos, una probable diferenciación de marca y que generalmente está relacionado con un mayor nivel de servicios o economías de escala y liderazgo tecnológico. El eje horizontal está dado por los segmentos de los clientes objetivos, y refleja el gra-

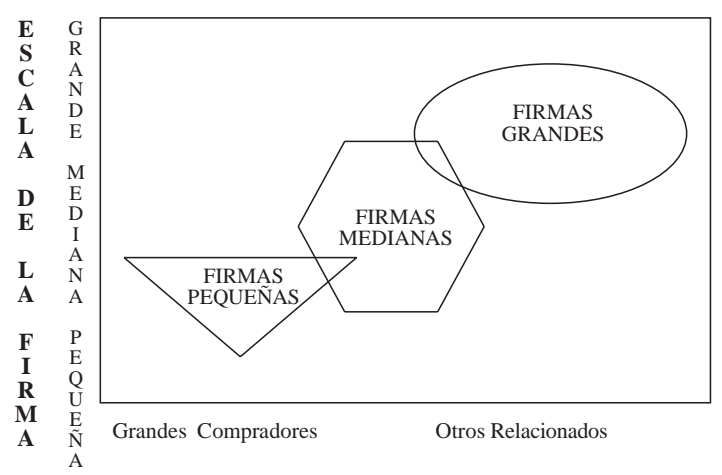

Figura 2. Mapa de los grupos estratégicos de la industria.

Map of the strategic groups of the industry. do de interdependencia del mercado para el conjunto de grupos estratégicos.

Los bajos índices de rentabilidad y las bajas tarifas desincentivan la formación de nuevos grupos estratégicos. Se espera sólo la redistribución o reacomodación de los grupos estratégicos de escala inferior. Los grandes se seguirán potenciando a través de la diferenciación tecnológica y la mejora de instalaciones para la reducción de costos. La situación actual de rentabilidad y de tarifas privilegiará y hará permanecer en el negocio sólo a quienes demuestren eficiencia, innovación y bajos costos.

Las firmas del grupo estratégico de bajo tamaño difícilmente lograrán desarrollar una escala rentable, por lo que tenderán a salir del negocio o reubicarse en segmentos de servicio temporal, a menos que desarrollen de forma sostenida alianzas.

Las firmas medianas están en la incertidumbre y dependerá de ellas, sus recursos y capacidades, el éxito en el futuro. Su misión es aumentar su escala. Sólo de esta manera podrán alcanzar niveles de eficiencia que les garanticen crecimiento permanente y estabilidad.

Para comprender las razones del éxito en las firmas se definieron cinco actividades en las cuales las firmas exitosas han desarrollado a través del tiempo capacidades superiores, de difícil imitación y sustitución, lo que les permite una posición competitiva sostenida en el tiempo. Estas capacidades se transforman así en activos no transables, desarrollados y acumulados dentro de la firma, socialmente complejos y que han nacido de las habilidades de las organizaciones y del aprendizaje interno.

1. Conocimiento Tecnológico y Mecánico de Equipos: una de las actividades que distingue a las firmas exitosas es la capacidad que han desarrollado en Equipos y Tecnología. En el mercado se comercializan al menos 12 marcas de camiones apropiados para el transporte de trozos. En su trayectoria las firmas han comprendido que la concentración en pocas marcas les facilita el desarrollo de programas de mantenimiento, especialización de personal, relación con proveedores y representantes, rapidez en el diagnóstico de fallas y conocimiento de los costos.

La relación privilegiada con proveedores, establecida y consolidada a través del tiempo, ha 
permitido a las firmas incorporar modificaciones en los equipos, mejorando el rendimiento técnico de ellos, aumentando su disponibilidad y evitando un desgaste prematuro de piezas y partes, y por lo tanto, generando un escenario propicio para el desempeño económico.

El conocimiento tecnológico desarrollado por el personal que realiza las mantenciones y reparaciones de los equipos, favorecido por la decisión de concentración de la flota en no más de dos o tres marcas, permite orientar los esfuerzos de mantenimiento haciéndolos más efectivos y eficientes. Esto se traduce en que las firmas exitosas logran mejores indicadores de disponibilidad efectiva que otras firmas, ya que sus camiones están menos tiempo en taller. Calculan que sus camiones están en taller en promedio sólo la mitad del tiempo que los camiones de las otras firmas. Mantener bajo control el desempeño mecánico de los camiones permite a la dirección de las firmas explorar otras oportunidades de ahorro complementarias.

2. Asignación Eficiente de Programas: las firmas reciben diariamente órdenes de movimiento de cargas. Estas órdenes implican la asignación de camiones y su desplazamiento desde diversos orígenes o lugares de carga a múltiples destinos o lugares de descarga. Una buena asignación de viajes debe considerar la relación de distancias recorridas con y sin carga, la jornada laboral razonable de los conductores, los equipos técnica y económicamente adecuados a las rutas, la puntualidad horaria en la carga y descarga y finalmente el cumplimiento agregado de los viajes asignados. La labor de asignación es eficiente en la medida en que las unidades no recorran vacíos una mayor distancia que cargados, ahorrando así en insumos. Pero también debe ser eficaz para cumplir con los horarios fijados para la carga y descarga. La experiencia parece ser el principal factor de éxito para las personas que realizan esta función.

Algo complementario dice relación con los conductores asignados. En este sentido enviar los conductores mejor preparados para las características de la ruta permitirá obtener un mejor desempeño técnico y económico de los equipos. Es importante aquí destacar los esfuerzos que estas firmas han desplegado para ajustar el desempeño de sus conductores a una ley laboral compleja, en que la jornada de los conductores tiene indefiniciones, como los tiempos de espera en tierra o a bordo y con períodos de descanso variable de acuerdo a las horas de conducción.

Una actividad adicional que es común en todas las firmas exitosas es el grado de comunicación en línea que se tiene con los equipos y conductores. El tener un "estado conocido" de la flota, incluidos los conductores, mejora las posibilidades de asignación. Indistintamente el grupo estratégico, las firmas medianas y grandes operan con una central de despacho durante las 24 horas del día, siguiendo así el avance de las operaciones permanentemente.

Otra serie de variables de menor control deben ser conocidas y ponderadas por estos niveles operativos, entre ellas, dificultades de tránsito inherente a las rutas, horarios peak y calidad de usuarios, velocidades medias de desplazamiento, velocidades máximas permitidas, problemas de visibilidad nocturna, escabrosidad y diseño de curvas y problemas con los equipos de carga.

3. Compromiso de Conductores y Mecánicos: el desarrollo de esta capacidad permite la consecución de otras actividades clave como son la ocupación intensiva de equipos e instalaciones, el cumplimiento de los programas y la eficiencia en costos fijos y variables.

Los factores indicados como relevantes en esta actividad clave dicen relación con la rotación y capacitación de conductores y mecánicos, el compromiso con el éxito del negocio y el consecuente reconocimiento de logros.

Las firmas exitosas han logrado mantener una alta permanencia de su personal. Los niveles de rotación no exceden al 5\% anual. Esto resulta ser una variable fundamental para mantener el conocimiento y experiencia al interior de la firma. El nivel de formación de los conductores representa un obstáculo para la consecución de baja rotación. Expectativas de mejores sueldos a veces son atractivos de corto plazo que son más fuertes que condiciones higiénicas de trabajo, camiones asignados o relaciones laborales. Otros beneficios de la menor rotación de conductores tienen relación con la rápida ubicación en los predios de los puntos de carga y descarga, el reconocimiento de las rutas y sus problemas inherentes y los sistemas y procedimientos de trabajo exigidos por los clientes.

Con mecánicos estables será más fácil reconocer las fallas de los equipos y establecer con se- 
guridad los plazos de reparación, solicitar con certeza los repuestos necesarios y cuidar los imponderables con los cuales sólo el personal de mantenimiento está familiarizado.

Acciones como la conducción cuidadosa de los camiones, evitando el consumo excesivo de combustible y el desgaste prematuro de neumáticos ayudan a controlar los costos y mejoran el margen del negocio. Asimismo, tener disposición a cumplir los viajes asignados y solucionar en forma independiente los problemas menores que presentan los equipos son factores que ayudan al éxito de la firma. La administración de las firmas exitosas reconoce lo comentado anteriormente y están dispuestas a recompensar este desempeño.

4. Ocupación Intensiva de Equipos e Instalaciones: en la industria de servicios de transporte forestal el capital invertido en equipos constituye el activo fijo más importante. Las firmas exitosas buscan optimizar el uso del capital en equipos e instalaciones, así, con más unidades transportadas y vendidas, el costo fijo unitario disminuye considerablemente y ubican a la firma en posiciones de privilegio en costos e ingresos totales. Los programas de mantenimiento y procedimientos de uso son gravitantes para evitar que un uso intensivo del capital, que permite tener un proyecto con un período más corto de recuperación de la inversión, provoque un desgaste prematuro de los camiones y reduzca dramáticamente el valor residual de ellos.

Las firmas han buscado acuerdos con sus clientes para poder operar con sus camiones en forma ininterrumpida. Hoy el doble turno es una práctica común a las principales empresas forestales y en tal dirección se ha movido la administración de las firmas. El proceso de llegar a trabajar en forma continua no es fácil. Las firmas reportan entre 6 y 12 meses de aprendizaje.

Un aspecto particularmente complicado ha sido la incorporación de nuevos conductores y el uso compartido de los camiones, aún las firmas exitosas en el manejo del personal han sufrido trastornos por este motivo.

5. Eficiencia en Costos Fijos y variables: como se discutió en los capítulos anteriores, la industria de servicios de transporte forestal está caracterizada por una alta competencia en costos. Las fuerzas de la industria se mueven en función de ello y el desarrollo y fortalecimiento de las capacidades siempre conlleva beneficios de aho- rro en costos o en la generación de mayores ventas y por lo tanto ingresos.

Una apropiada selección de camiones, además concentrada en pocas marcas, les ha evitado largas detenciones por reparación, mantienen una bodega satisfactoria de repuestos y el personal experto aplica programas de mantenimiento eficientes manteniendo altas disponibilidades mecánicas.

Las relaciones privilegiadas con los proveedores les proporcionan a las firmas importantes oportunidades de negociación, han conseguido así insumos y repuestos a menor costo, mayores plazos de pago y extensión de garantías mecánicas en los equipos.

Finalmente, los conductores entrenados y motivados están dispuestos a ejecutar los programas asignados, mantienen hábitos seguros de conducción, se preocupan de las condiciones mecánicas de los camiones, evitan las pérdidas de tiempo, los desgastes excesivos de neumáticos, conducen buscando el máximo rendimiento del motor y desean que la firma sea exitosa.

Se presenta en la figura 3 un esquema o mapa con las cinco actividades más importantes que han permitido a las firmas exitosas mantener una posición competitiva a través del tiempo, destacan en fondo oscuro estas actividades claves y en fondo claro las actividades complementarias o de segundo orden. Además se muestran las conexiones e interconexiones entre todas ellas.

\section{CONCLUSIONES}

Por un concepto de tamaños relativos, siempre existirán 2 ó 3 clientes que conforman un monopsonio, determinando las condiciones de compra de los servicios.

El alto riesgo del negocio, las bajas barreras de entrada y altas barreras de salida hacen que en esta industria el crecimiento progresivo prime sobre las entradas agresivas. No existen productos sustitutos o competidores que amenacen a las firmas competidoras.

El tamaño de las firmas condiciona la relación entre ellas y proveedores y clientes. Por una parte favorece el acceso privilegiado a insumos, fuentes de financiamiento, nuevas tecnologías y precios. Por la otra permite establecer contratos duraderos y privilegiados con los clientes. 


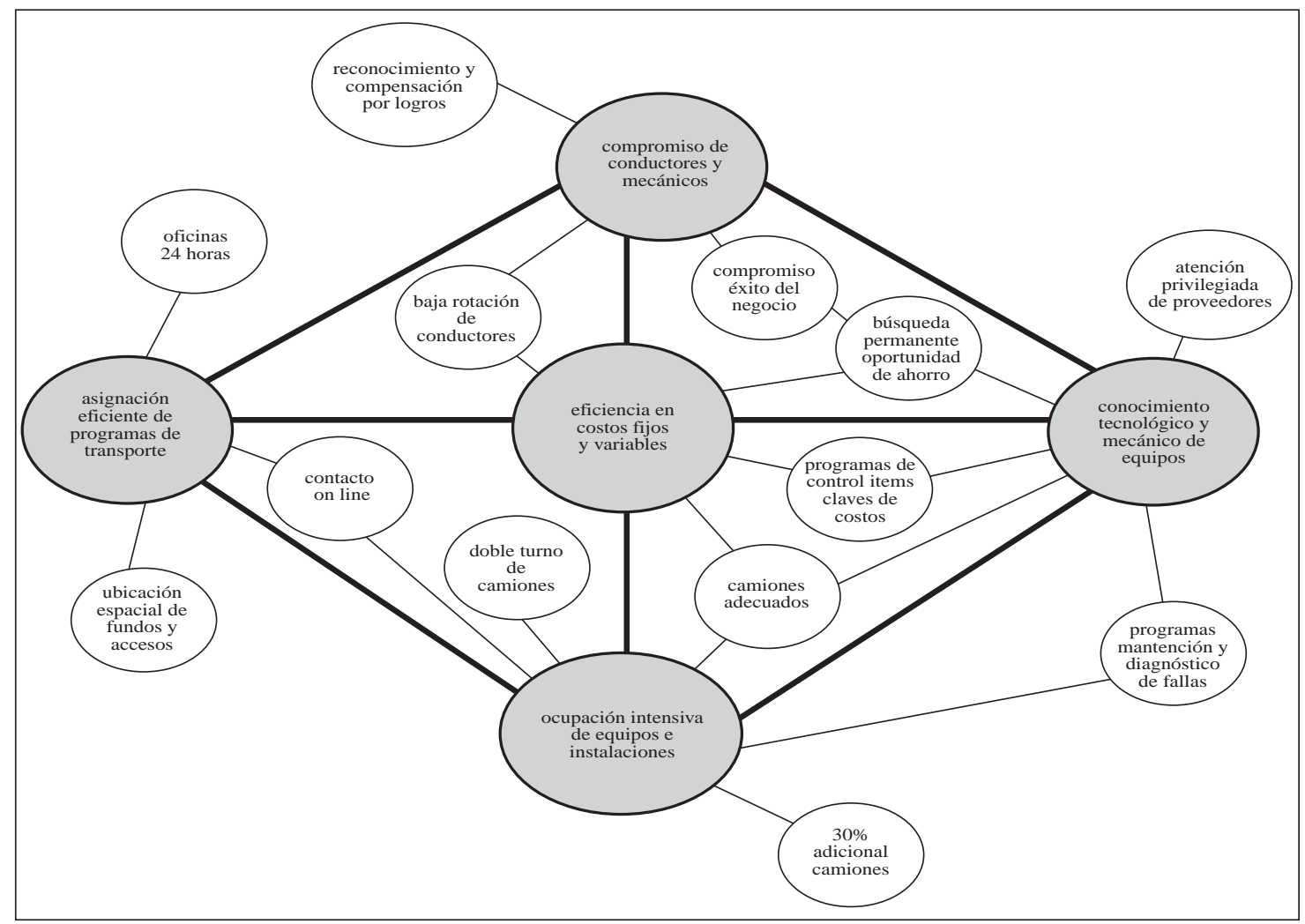

Figura 3. Mapa de actividades clave y relaciones.

Map of key activities and relations.

Las firmas grandes tienen criterios de inversión y desarrollo que las hace estar considerablemente mejor posicionadas que las medianas y pequeñas. La búsqueda de profesionalización, control de gestión y costos, calidad de servicio y productividad es un común denominador de todas estas firmas.

Además las firmas grandes están en mejor posición para buscar integración, vertical u horizontal, que les permitirá aprovechar economías de escala o ámbito.

La estrategia de liderazgo en costos domina en esta industria, por lo tanto el tamaño o escala es un factor relevante para mejorar la posición competitiva con proveedores y clientes. Esta escala representa el cúmulo de decisiones y compromisos estratégicos con la industria del transporte forestal a través del tiempo.

Las firmas más exitosas en la industria del transporte forestal realizan mejor una serie de actividades estratégicas, que les permite mantener su posición privilegiada y sostenible en la indus- tria, distanciándose así de sus competidoras de los mismos u otros grupos estratégicos. Este desarrollo involucra un compromiso que significa un alto grado de irreversibilidad y obligaciones con el desempeño futuro.

\section{BIBLIOGRAFIA}

(1) CRAINIC T.G., G. LAPORTE. Planning Models for Freight Transportation. European Journal of Operational Research (Holanda), 1997, p. 409-438.

(2) HAKKILA, P. Procurement of Timber for The Finnish Forest Industries. Helsinki: Finish Forest Research Institute, 1995, $128 \mathrm{p}$.

(3) BACKHOUSE, P. Diagnóstico del Transporte Forestal en Carreteras de la $7^{a}$ a la $10^{a}$ Región del País. Concepción, 1996, 181 p.

(4) PORTER, M. Ventaja Competitiva: Creación y Sostenimiento de un Desempeño Superior. $2^{\mathrm{a}}$ ed, México D. F.: CECSA, 1987, $550 \mathrm{p}$.

(5) ANDALAFT, A., J. PERRET. Estudio del Mercado de Transporte Forestal. Concepción: Universidad de Concepción, 2000, 117 p.

(6) HILL, C., G. JONES. Administración Estratégica: un enfoque integrado. $3^{\mathrm{a}}$ ed, Bogotá: Mc Graw Hill Interamericana S.A., 1996, 540 p. 
(7) NELSON, R., S. WINTER. An Evolutionary Theory of Economics Change. In: FOSS, N. Resources Firms and Strategies: A Reader in the Resources Based Perspective. New York: Oxford University Press, 1997, p. 82-99.

(8) FOSS, N. Resources Firms and Strategies: A Reader in the Resources Based Perspective. New York: Oxford University Press, 1997, 378 p.

(9) PETERAF M. The Cornerstones of Competitive Advantage: a Resourced Based View. Strategic Management Journal (USA), 1993, vol. 14, p. 179-191.

(10) MAHONEY J., J. PANDIAN. The Resource-Based View Within the Conversation of Strategic Management. Strategic Management Journal (USA), 1992, vol. 13, p. 363-380

(11) MARKIDES C., P. WILLIAMSON. Related diversification, core competences, and corporate performance. In: FOSS, N. Resources Firms and Strategies: A Reader in the Resources Based Perspective. New York: Oxford University Press, 1997, p. 327-341.

(12) BARNEY J. Strategic Factor Markets: Expectations, Luck, and Business Strategy. Management Science (USA), 1986, vol. 32, No 10, p. 1231-1241.

(13) CHATTERJEE S., B. WERNERFELT. The link between Resources and type of Diversification: theory and evidence. Strategic Management Journal (USA), 1991, vol. 12 , p. $33-48$

(14) KOGUT B., U. ZANDER. Knowledge of the Firm, Combinative Capabilities and the Replication of Technology. In: FOSS, N. Resources Firms and Strategies: A Reader in the Resources Based Perspective. New York: Oxford University Press, 1997, p. 306-326.

(15) GHEMAWAT, P. La Estrategia en el Panorama del Negocio: texto y casos. $1^{\mathrm{a}}$ ed, México D.F.: Prentice Hall, 2000, 134 p.

Recibido: 29.09 .03

Aceptado: 06.09.05 